\title{
Expanding RNA physiology: microRNAs in a unicellular organism
}

\author{
Haruhiko Siomi ${ }^{1}$ and Mikiko C. Siomi \\ Institute for Genome Research, University of Tokushima, 3-18-15 Kuramoto, Tokushima, 770-8503 Japan
}

Until recently, the world viewed through the eyes of molecular biologists seemed simple with a well-known slogan hailing a central dogma: "DNA makes RNA makes protein." This has been interpreted to mean that genetic output is entirely or almost entirely transacted by proteins (Mattick 2004). However, within a few years of the discovery of RNA interference (RNAi) (Fire et al. 1998), an explosion of data has lifted the veil off many previous puzzling findings. Thus, our view of the field was irrevocably changed with a new slogan-that went alongside the classical central dogma-"RNA makes small RNA makes no protein" (Fig. 1). Sequence information in long RNA transcripts is converted into small, 20- to 30-nucleotide (nt)-long, non-protein-coding RNAs such as microRNAs (miRNAs) and small interfering RNAs (siRNAs). These small RNAs trigger various forms of sequence-specific gene silencing, including RNA cleavage and degradation, cleavage-independent mRNA decay, translational repression, methylation of protein-coding DNA, and heterochromatin formation in a variety of eukaryotic organisms ranging from fission yeast, plants, fungi, nematode, and fly to humans. This process is now collectively referred to as RNA silencing (Tomari and Zamore 2005; Zaratiegui et al. 2007). In addition to classical small non-proteincoding RNAs-including tRNAs, small nuclear RNAs (snRNAs), and small nucleolar RNAs (snoRNAs)-recent studies have shown that our cells express a surprisingly large number of new regulatory small RNAs that seem to be particularly abundant in roles that direct the binding of protein complexes to specific nucleic acid sequences (Hüttenhofer and Schattner 2006). These include miRNAs, several groups of natural or endogenous siRNAs, and Piwi-interacting RNAs (piRNAs) (Kim 2006). The ongoing efforts to uncover the full biological scope of RNA silencing have already modified our notions about how gene expression is controlled. It is becoming clear that RNA silencing comprises an important tier of gene expression in eukaryotes, enabling the integration and networking of complex suites of gene activity, thereby elaborating multicellular complexity (Bartel 2004; Kloosterman and Plasterk 2006).

The first small RNA trigger discovered in eukaryotes was the lin-4 miRNA, which was found by mapping a

${ }^{1}$ Corresponding author.

E-MAIL siomi@genome.tokushima-u.ac.jp; FAX 81-88-6339451.

Article is online at http://www.genesdev.org/cgi/doi/10.1101/gad.1559707. developmental timing (heterochronic) mutant Caenorhabditis elegans locus (Lee et al. 1993). The discovery of the phylogenetic conservation of let-7 miRNA then really opened up the field (Pasquinelli et al. 2000). Thousands of miRNAs have now been identified in various multicellular organisms (miRBase; Griffiths-Jones et al. 2006), and an astonishing number of miRNA genes have been predicted to exist in our genome (Miranda et al. 2006). Transcripts of genes encoding self-complementary RNA that forms imperfect hairpins, termed primary microRNA (pri-miRNA), are cleaved by the DroshaPasha/DGCR8 complex in the nucleus to generate premiRNA. The pre-miRNA is exported to the cytoplasm and further processed by Dicer into an 21- to 23-nt miRNA duplex. Then, one strand over the other is often preferentially loaded into a RNA-induced silencing complex (RISC), which contains at its core a member of the Argonaute family of proteins (Parker and Barford 2006). Once incorporated into the silencing complex, mature miRNAs interact with target mRNAs at specific sites to induce cleavage of the message, cleavage-independent mRNA decay, or inhibit translation (Tomari and Zamore 2005; Pillai et al. 2007). Cleavage of mRNA targets is catalyzed by Argonaute proteins (Liu et al. 2004; Parker and Barford 2006). In both animals and plants, miRNAs play important roles in diverse developmental processes, including developmental timing, cell death, cell proliferation, asymmetric cell fate decision, organogenesis, and patterning of the nervous system. However, the biological functions of most miRNAs remain unknown (Alvarez-Garcia and Miska 2005; Jones-Rhoades et al. 2006). Recent studies have shown that miRNAs target $30 \%$ or more of all animal protein-coding genes, most of which are regulated through base pairing between specific sites in the 3' untranslated region of the messenger RNAs (mRNAs) and a small region termed the "seed" (nucleotides $1-8$, from the $5^{\prime}$ end) near the $5^{\prime}$ end of the miRNA (Brennecke et al. 2005; Lewis et al. 2005; Xie et al. 2005). These rather lax criteria can result in numerous targets being predicted for a given miRNA. Many genes have several target sites for either one miRNA or a few different miRNAs. Additionally, many miRNAs are expressed in a cell type- or tissue-specific manner, and miRNAs and their targets have, to a large extent, mutually exclusive expression patterns ("para-expression") (Farh et al. 2005; Stark et al. 2005). Therefore, the general function of miRNAs may be that miRNAs diversify cell types or organ types by fine-tuning the proteome, and then retain 


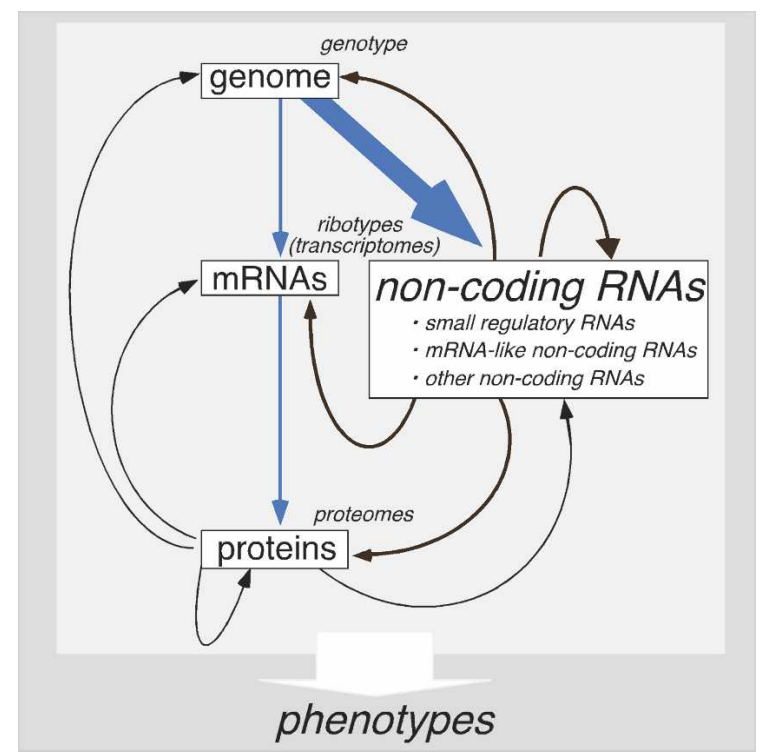

Figure 1. RNA physiology. Recent studies show that the vast majority of our genome is transcribed (e.g., Carninci et al. 2005; Manak et al. 2006). This in turn produces a surprisingly large number of functional non-protein-coding RNAs, including small regulatory RNAs (Prasanth and Spector 2007). These observations have led to a new concept: that lying behind the origin of complexity of higher organisms is the dramatic expansion of the non-protein-coding RNA inventory, including the absolute number of siRNAs and miRNAs, rather than an increase in the protein-encoding inventory (Mattick 2004).

terminal differentiation programs in a stable end state by dumping expression of genes that should not be expressed in particular cell types (Kloosterman and Plasterk 2006). The rapidly expanding repertoire of miRNAs and their targets suggests that miRNAs played a role in the adaptive diversification of pre-existing transcriptional and cell-cell signaling pathways required for the evolution of new regulatory circuits and, ultimately, new patterns within body plans. Thereby, miRNAs appear to drive animal and plant diversity (Carthew 2006; Ambros and Chen 2007; Niwa and Slack 2007). Consistent with this notion that miRNAs are global regulators of cell differentiation and patterning, miRNAs have thus far only been identified in multicellular organisms. They are notably absent from unicellular organisms including Schizosaccharomyces pombe and Tetrahymena thermophila, in which RNA silencing mechanisms are known to operate. However, in this issue of Genes \& Development, Qi and coworkers (Zhao et al. 2007) add an exciting new twist to this developing story, showing that the unicellular green alga Chlamydomonas reinhardtii encodes many miRNAs.

Long known for their roles in motility, flagella (or cilia) are increasingly being recognized as sites for transmitting signals to the cytoplasm and nuclei to control gene expression, cell function, animal development, and behavior (Snell et al. 2004; Scholey and Anderson 2006). The unicellular biflagellate alga $C$. reinhardtii has been a productive model system for molecular genetic studies of flagellar assembly and function, as well as of basal body function, for more than five decades, mainly because its flagellated vegetative cells are haploid and its mutants can be genetically analyzed by sexual crosses between different strains (Schroda 2006). Mating is initiated when the cells are starved for nitrogen and involves the shedding of the cell wall prior to cytoplasmic fusion of opposite mating types. After nuclear and chloroplast fusion, flagella are lost and a zygotic cell wall begins to form. Meiosis is initiated in zygotes by reintroduction of nutrients and is completed to produce four meiotic zoospores. The development of reliable procedures for transformation has also facilitated the study of various aspects of cell biology of C. reinhardtii. Additionally, RNAi has been shown to be an effective reverse genetic approach in this organism. This indicates that $C$. reinhardtii possesses functional RNAi machinery.

Zhao et al. (2007) now report the identification and characterization of small RNAs in C. reinhardtii using a highly parallel pyrosequencing methodology (Margulies et al. 2005). Computational studies show that among 4182 unique small RNA sequences identified, 200 species were derived from genomic sequences with the potential to form hairpin structures that meet the requirements for an miRNA precursor. These RNAs share several common features with miRNAs, including having a $5^{\prime}$ phosphate and a preference for uracil at the 5 ' end. In addition, several of the miRNAs identified have a sequenced pairing miRNA ${ }^{\star}$ located in the opposite arm of the precursor, which is capable of forming a duplex bearing the 2-nt 3' overhang - the hallmark of Dicer cleavage (Tomari and Zamore 2005; Kim 2006). These findings show that $C$. reinhardtii encodes miRNAs - the first evidence of miRNAs in a unicellular organism.

None of the C. reinhardtii miRNAs had an ortholog in other green algae, plants, or animals, suggesting that $C$. reinhardtii miRNA genes may have arisen independently after splitting from a common lineage. A substantial number of the C. reinhardtii miRNAs are located in relatively long hairpins, many of which have the potential to produce multiple small RNAs. These observations are similar to recent results from plants that suggest that some miRNA genes evolve de novo through inverted duplication of their future target genes (Allen et al. 2004). This hypothesis predicts that recently evolved, and therefore presumably nonconserved, miRNAs might still contain long segments with high similarity to the target gene sequence. Indeed, a number of nonconserved Arabidopsis thaliana miRNA loci have been identified to fulfill these criteria (Allen et al. 2004; Rajagopalan et al. 2006). Whether some of the C. reinhardtii miRNAs fulfill the criteria remains to be determined. Given their highly evolving nature, newly evolved miRNAs are ideally suited to convey rapid adaptation to an environment and, therefore, will probably be more abundant in their stress responses (Voinnet 2004). Interestingly, computational studies have also predicted many genes encoding flagellar-associated proteins as targets for the C. reinhardtii miRNAs. Chlamydomonas cells shed their flagella in response to many stressful conditions, presum- 
ably serving a protective function for cells in the particular environment. Then, after the shedding, Chlamydomonas cells begin to regenerate flagella (Lefebvre 1995).

Are the C. reinhardtii miRNAs functional? Zhao et al. (2007) fractionated total extracts from C. reinhardtii cultures by gel filtration and found that the $C$. reinhardtii miRNAs exist in complexes with a molecular size of $\sim 150 \mathrm{kDa}$, a size that is similar to that of minimal RISC in human and Drosophila cells (Martinez et al. 2002). If miRNAs have sufficient complementarity to the target RNA, they can direct cleavage of the target between 10 and $11 \mathrm{nt}$ from the $5^{\prime}$ end of the miRNA, as is the case for siRNAs in RNAi (Yekta et al. 2004). C. reinhardtii miRNAs were cofractionated with the site-specific cleavage activity of their predicted mRNA targets, much like "Slicer" activity of some Argonaute proteins (Parker and Barford 2006). The Chlamydomonas genome encodes three Dicer-like and at least two Argonaute proteins (Schroda 2006). It remains to be determined whether an Argonaute protein resides in C. reinhardtii miRNP complexes and which cellular processes they are involved in. Do the C. reinhardtii miRNAs act to regulate genes involved in, for example, specification of flagellar assembly, functioning in a manner analogous to cell fate decisions in multicellular organisms that are triggered by signal transduction activity (Bartel 2004; Carthew 2006; Kloosterman and Plasterk 2006)? It is probably noteworthy that Chlamydomonas gametes use their flagella as sensory transducers during fertilization (Snell et al. 2004; Scholey and Anderson 2006). The interaction between the flagella of cells of opposite mating types initiates a series of morphological changes, including the release of their extracellular matrix (cell wall), modification and elongation of the flagellar tip, and erection of microvillus-like cell fusion organelles. Some of the C. reinhardtii miRNAs appear to be differentially expressed in a vegetative state and in gametes, suggesting that they might play roles in gametic differentiation. It will be interesting to see how these processes are affected when some or all of the C. reinhardtii miRNAs are depleted, and to analyze whether certain transcripts or proteins are differently expressed in such miRNA-depleted and control gametes.

In addition to miRNAs, Zhao et al. (2007) identified a large number of endogenous siRNAs. Their $5^{\prime}$ ends also show the strong preference for uracil that is characteristic of small RNAs (Kim 2006). They are derived from various locations including protein-coding genes and intergenic regions. Many of them are enriched in several genomic loci and phased relative to each other, reminiscent of plant trans-acting siRNAs (tasiRNAs), whose biogenesis requires miRNA-directed cleavage (Allen et al. 2005; Yoshikawa et al. 2005; Axtell et al. 2006). Although many endogenous siRNAs are products of RNAdependent RNA polymerases (RdRPs) in plants and $C$. elegans (Cerutti and Casas-Mollano 2006; Vazquez 2006), Chlamydomonas lacks an RdRP in its genome (Schroda 2006). Very few C. reinhardtii siRNAs arise from repetitive sequences and transposons. In fact, repetitive sequences are underrepresented. This situation appears similar to mammalian piRNAs (Aravin et al. 2006; Girard et al. 2006; Lau et al. 2006). It remains to be determined whether these endogenous siRNAs in C. reinhardtii use a molecular mechanism similar to that of mammalian piRNAs to silence portions of the genome (Kim 2006) or whether they use a molecular mechanism similar to that of plant tasiRNAs to silence messages from loci that are unrelated to those from which the siRNAs derive (Vazquez 2006).

There are many more questions ensuing from these studies. Are miRNAs found in unicellular organisms other than C. reinhardtii? The giant unicellular alga Acetabularia may be one such candidate. Control of developmental morphogenesis in this enormous cell $(2-4 \mathrm{~cm})$ was studied by J. Hämmerling in the 1930s (Hämmerling 1934; Mandoli 1998), but the morphogenetic signals involved in his intriguing experiments are still to be explored using modern molecular techniques (Mandoli 1998). Are other classes of small RNAs found in C. reinhardtii? Zhao et al. (2007) isolated small RNAs from C. reinhardtii cultures under vegetative growth conditions. By analogy with piRNAs in the mammalian germline, C. reinhardtii gametes may express specific classes of small RNAs. Is there a class of siRNAs in $C$. reinhardtii that can direct chromatin modifications in the newly replicated "zygotic" nucleus and thus induce heritable silencing? Perhaps the most crucial question is how the surprisingly large number of siRNAs and miRNAs in C. reinhardtii connect between genotype and phenotype. Further investigation should reveal the physiology of small RNAs in C. reinhardtii and help expand our understanding of the physiology of small RNAs in multicellular organisms.

\section{Acknowledgments}

We thank Yukihide Tomari and Takafumi Sunohara for comments. Work in our laboratories was supported by the Ministry of Education, Culture, Sports, Science, and Technology of Japan (MEXT) and the New Energy and Industrial Technology Development Organization (NEDO).

\section{References}

Allen, E., Xie, Z., Gustafson, A.M., Sung, G.H., Spatafora, J.W., and Carrington, J.C. 2004. Evolution of microRNA genes by inverted duplication of target gene sequences in Arabidopsis thaliana. Nat. Genet. 36: 1282-1290.

Allen, E., Xie, Z., Gustafson, A.M., and Carrington, J.C. 2005. microRNA-directed phasing during trans-acting siRNA biogenesis in plants. Cell 121: 207-221.

Alvarez-Garcia, I. and Miska, E.A. 2005. MicroRNA functions in animal development and human disease. Development 132: 4653-4662.

Ambros, V. and Chen, X. 2007. The regulation of genes and genomes by small RNAs. Development 134: 1635-1641.

Aravin, A., Gaidatzis, D., Pfeffer, S., Lagos-Quintana, M., Landgraf, P., Iovino, N., Morris, P., Brownstein, M.J., KuramochiMiyagawa, S., Nakano, T., et al. 2006. A novel class of small RNAs bind to MILI protein in mouse testes. Nature 442: 203-207.

Axtell, M.J., Jan, C., Rajagopalan, R., and Bartel, D.P. 2006. A twohit trigger for siRNA biogenesis in plants. Cell 127: 565-577. 
Bartel, D.P. 2004. MicroRNAs: Genomics, biogenesis, mechanism, and function. Cell 116: 281-297.

Brennecke, J., Stark, A., Russell, R.B., and Cohen, S.M. 2005. Principles of microRNA-target recognition. PLoS Biol. 3: e85.

Carninci, P., Kasukawa, T., Katayama, S., Gough, J., Frith, M.C., Maeda, N., Oyama, R., Ravasi, T., Lenhard, B., Wells, C., et al. 2005. The transcriptional landscape of the mammalian genome. Science 309: 1559-1563.

Carthew, R.W. 2006. Gene regulation by microRNAs. Curr. Opin. Genet. Dev. 16: 203-208.

Cerutti, H. and Casas-Mollano, J.A. 2006. On the origin and functions of RNA-mediated silencing: From protists to man. Curr. Genet. 50: 81-99.

Farh, K.K., Grimson, A., Jan, C., Lewis, B.P., Johnston, W.K., Lim, L.P., Burge, C.B., and Bartel, D.P. 2005. The widespread impact of mammalian MicroRNAs on mRNA repression and evolution. Science 310: 1817-1821.

Fire, A., Xu, S., Montgomery, M.K., Kostas, S.A., Driver, S.E., and Mello, C.C. 1998. Potent and specific genetic interference by double-stranded RNA in Caenorhabditis elegans. Nature 391: 806-811.

Girard, A., Sachidanandam, R., Hannon, G.J., and Carmell, M.A. 2006. A germline-specific class of small RNAs binds mammalian Piwi proteins. Nature 442: 199-202.

Griffiths-Jones, S., Grocock, R.J., van Dongen, S., Bateman, A., and Enright, A.J. 2006. miRBase: microRNA sequences, targets and gene nomenclature. Nucleic Acids Res. 34: D140-D144.

Hämmerling, J. 1934. Über formbildende Substanzen bei Acetabularia mediterranea, ihre räumliche und zeitliche Verteilung und ihre Herkunft. WIlhelm RouxArch. EntwMech. Org. 131: 1-81.

Hüttenhofer, A. and Schattner, P. 2006. The principles of guiding by RNA: Chimeric RNA-protein enzymes. Nat. Rev. Genet. 7: 475-482.

Jones-Rhoades, M.W., Bartel, D.P., and Bartel, B. 2006. MicroRNAs and their regulatory roles in plants. Annu. Rev. Plant Biol. 57: 19-53.

Kim, V.N. 2006. Small RNAs just got bigger: Piwi-interacting RNAs (piRNAs) in mammalian testes. Genes \& Dev. 20: 1993-1997.

Kloosterman, W.P. and Plasterk, R.H. 2006. The diverse functions of microRNAs in animal development and disease. Dev. Cell 11: 441-450.

Lau, N.C., Seto, A.G., Kim, J., Kuramochi-Miyagawa, S., Nakano, T., Bartel, D.P., and Kingston, R.E. 2006. Characterization of the piRNA complex from rat testes. Science 313: 363-367.

Lee, R.C., Feinbaum, R.L., and Ambros, V. 1993. The C. elegans heterochronic gene lin-4 encodes small RNAs with antisense complementarity to lin-14. Cell 75: 843-854.

Lefebvre, P.A. 1995. Flagellar amputation and regeneration in Chlamydomonas. Methods Cell Biol. 47: 3-7.

Lewis, B.P., Burge, C.B., and Bartel, D.P. 2005. Conserved seed pairing, often flanked by adenosines, indicates that thousands of human genes are microRNA targets. Cell 120: 15-20.

Liu, J., Carmell, M.A., Rivas, F.V., Marsden, C.G., Thomson, J.M., Song, J.J., Hammond, S.M., Joshua-Tor, L., and Hannon, G.J. 2004. Argonaute2 is the catalytic engine of mammalian RNAi. Science 305: 1437-1441.

Manak, J.R., Dike, S., Sementchenko, V., Kapranov, P., Biemar, F., Long, J., Cheng, J., Bell, I., Ghosh, S., Piccolboni, A., et al. 2006. Biological function of unannotated transcription during the early development of Drosophila melanogaster. Nat. Genet. 38: 1151-1158.

Mandoli, D.F. 1998. Whatever happened to Acetabularia? Bringing a once-classic model system into the age of molecu- lar genetics. Int. Rev. Cytol. 182: 1-67.

Margulies, M., Egholm, M., Altman, W.E., Attiya, S., Bader, J.S., Bemben, L.A., Berka, J., Braverman, M.S., Chen, Y.J., Chen, Z., et al. 2005. Genome sequencing in microfabricated highdensity picolitre reactors. Nature 437: 376-380.

Martinez, J., Patkaniowska, A., Urlaub, H., Luhrmann, R., and Tuschl, T. 2002. Single-stranded antisense siRNAs guide target RNA cleavage in RNAi. Cell 110: 563-574.

Mattick, J.S. 2004. RNA regulation: A new genetics? Nat. Rev. Genet. 5: 316-323.

Miranda, K.C., Huynh, T., Tay, Y., Ang, Y.S., Tam, W.L., Thomson, A.M., Lim, B., and Rigoutsos, I. 2006. A pattern-based method for the identification of MicroRNA binding sites and their corresponding heteroduplexes. Cell 126: 1203-1217.

Niwa, R. and Slack, F.J. 2007. The evolution of animal microRNA function. Curr. Opin. Genet. Dev. doi: 10.1016/ j.gde.2007.02.004.

Parker, J.S. and Barford, D. 2006. Argonaute: A scaffold for the function of short regulatory RNAs. Trends Biochem. Sci. 31: 622-630.

Pasquinelli, A.E., Reinhart, B.J., Slack, F., Martindale, M.Q., Kuroda, M.I., Maller, B., Hayward, D.C., Ball, E.E., Degnan, B., Muller, P., et al. 2000. Conservation of the sequence and temporal expression of let-7 heterochronic regulatory RNA. Nature 408: 86-89.

Pillai, R.S., Bhattacharyya, S.N., and Filipowicz, W. 2007. Repression of protein synthesis by miRNAs: How many mechanisms? Trends Cell Biol. 17: 118-126.

Prasanth, K.V. and Spector, D.L. 2007. Eukaryotic regulatory RNAs: An answer to the 'genome complexity' conundrum. Genes \& Dev. 21: 11-42.

Rajagopalan, R., Vaucheret, H., Trejo, J., and Bartel, D.P. 2006. A diverse and evolutionarily fluid set of microRNAs in Arabidopsis thaliana. Genes \& Dev. 20: 3407-3425.

Scholey, J.M. and Anderson, K.V. 2006. Intraflagellar transport and cilium-based signaling. Cell 125: 439-442.

Schroda, M. 2006. RNA silencing in Chlamydomonas: Mechanisms and tools. Curr. Genet. 49: 69-84.

Snell, W.J., Pan, J., and Wang, Q. 2004. Cilia and flagella revealed: From flagellar assembly in Chlamydomonas to human obesity disorders. Cell 117: 693-697.

Stark, A., Brennecke, J., Bushati, N., Russell, R.B., and Cohen, S.M. 2005. Animal MicroRNAs confer robustness to gene expression and have a significant impact on $3^{\prime} \mathrm{UTR}$ evolution. Cell 123: 1133-1146.

Tomari, Y. and Zamore, P.D. 2005. Perspective: Machines for RNAi. Genes \& Dev. 19: 517-529.

Vazquez, F. 2006. Arabidopsis endogenous small RNAs: Highways and byways. Trends Plant Sci. 11: 460-468.

Voinnet, O. 2004. Shaping small RNAs in plants by gene duplication. Nat. Genet. 36: 1245-1246.

Xie, X., Lu, J., Kulbokas, E.J., Golub, T.R., Mootha, V., LindbladToh, K., Lander, E.S., and Kellis, M. 2005. Systematic discovery of regulatory motifs in human promoters and 3' UTRs by comparison of several mammals. Nature 434: 338-345.

Yekta, S., Shih, I.H., and Bartel, D.P. 2004. MicroRNA-directed cleavage of HOXB8 mRNA. Science 304: 594-596.

Yoshikawa, M., Peragine, A., Park, M.Y., and Poethig, R.S. 2005. A pathway for the biogenesis of trans-acting siRNAs in Arabidopsis. Genes \& Dev. 19: 2164-2175.

Zaratiegui, M., Irvine, D.V., and Martienssen, R.A. 2007. Noncoding RNAs and gene silencing. Cell 128: 763-776.

Zhao, T., Li, G., Mi, S., Li, S., Hannon, G.J., Wang, X.-J., and Qi, Y. 2007. A complex system of small RNAs in the unicellular green alga Chlamydomonas reinhardtii. Genes \& Dev. (this issue) doi: $10.1101 /$ gad.1543507. 


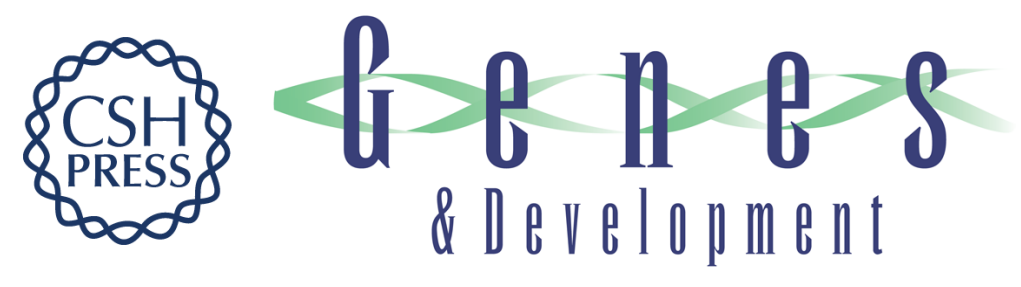

\section{Expanding RNA physiology: microRNAs in a unicellular organism}

Haruhiko Siomi and Mikiko C. Siomi

Genes Dev. 2007, 21:

Access the most recent version at doi:10.1101/gad.1559707

\section{Related Content}

References
A complex system of small RNAs in the unicellular green alga Chlamydomonas reinhardtii

Tao Zhao, Guanglin Li, Shijun Mi, et al.

Genes Dev. May, 2007 21:1190-1203

This article cites 48 articles, 13 of which can be accessed free at:

http://genesdev.cshlp.org/content/21/10/1153.full.html\#ref-list-1

Articles cited in:

http://genesdev.cshlp.org/content/21/10/1153.full.html\#related-urls

\section{License}

Email Alerting

Service
Receive free email alerts when new articles cite this article - sign up in the box at the top right corner of the article or click here.

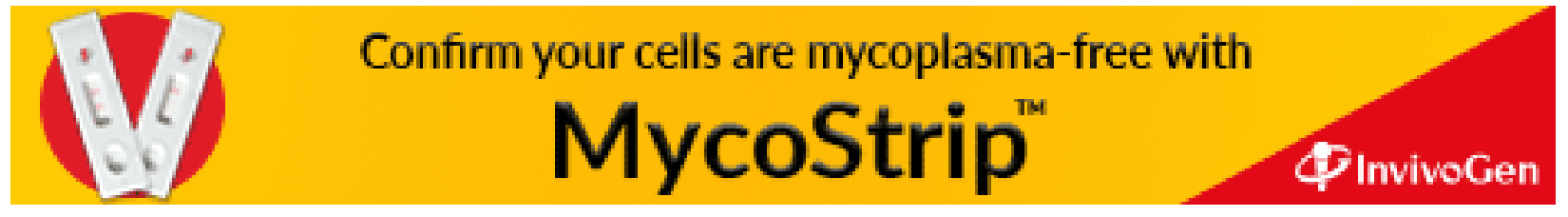

